\title{
Sunlight-driven photocatalysis of dissolved organic matter: Tracking by excitation emission matrix-parallel factor analysis and optimization using response surface methodology
}

\author{
Thao Thi Nguyen, Seong-Nam $\mathrm{Nam}^{\dagger}$ \\ Department of Civil and Environmental Engineering, Chung-Ang University, 84 Heukseok-ro, Dongjak-gu, Seoul, 06974, Republic of Korea
}

\begin{abstract}
This study investigates the photocatalysis of dissolved organic matter (DOM) under ZnO-assisted artificial sunlight irradiation. Response surface methodology (RSM) based on central composite design (CCD) was utilized for design of experiments with $\mathrm{ZnO}$ dosage and pH. Fluorescence excitation-emission matrices coupled with parallel factor analysis (EEM-PARAFAC), dissolved organic carbon (DOC), and UV/Vis spectroscopy were used to track the DOM degradation during photocatalysis. EEM-PARAFAC analysis decomposed fluorescent DOM into two components ( $\mathrm{C} 1$ and $\mathrm{C} 2$ ), identified as terrestrial humic-like organic matters. A pseudo-first-order DOM removal decreased with increased $\mathrm{ZnO}$ dosage, and were highest at $\mathrm{pH} 7$ and lowest at $\mathrm{pH}$ 4. Response surface models of DOC, $\mathrm{UV}_{254}, \mathrm{C} 1$ and $\mathrm{C} 2$ removals demonstrated statistically significant and well matched with a second-order polynomial equation based on analysis of variance (ANOVA). First-order terms were the highest contributor, in which $\mathrm{ZnO}$ dosage had the highest level of significance, to the DOM removal. The optimal conditions for the photocatalysis of DOM were found to be $\mathrm{ZnO} 0.3 \mathrm{~g} / \mathrm{L}$ and $\mathrm{pH} 10$, showing that the removals of $\mathrm{DOC}, \mathrm{UV}_{254}, \mathrm{C} 1$ and $\mathrm{C} 2$ were $57.9 \%, 94.5 \%$, 100\%, and 98.0\%, respectively. In addition, $\mathrm{ZnO}$ showed a good stability and better photodegradation efficiency than $\mathrm{TiO}_{2}$ in the $\mathrm{DOM}$ removal.
\end{abstract}

Keywords: Artificial Sunlight Irradiation, Central Composite Design (CCD), Dissolved Organic Matter (DOM), Parallel Factor Analysis (PARAFAC), Zinc Oxide $(\mathrm{ZnO})$

\section{Introduction}

Dissolved organic matter (DOM), found in every aquatic system, is a complex mixture of organic substances containing humic acids (HAs), fulvic acids (FA), aliphatic compounds, carbohydrates, and proteins [1-5]. Despite important roles of DOM in water bodies, an increase of DOM in surface water and wastewater has been a concern due to the potential negative impacts on the environment and human health.

DOM may have negative impacts on the water quality and overall efficiencies of treatment processes, such as increased coagulant and disinfectant demand, causing membrane fouling, causing yellow/brown color to water and cause taste and odor problems, promoted biological growth in the distribution system, increased disinfection by-products (DBPs) formation, and so on [1-3]. Especially, the primary concern of DOM present in water sources is related to the harmful DBPs generated from the disinfection process during drinking water treatment. The DBPs-like trihalomethanes (THMs) and haloacetic acids (HAAs) are potential carcinogens, mutagenic, teratogenicity to humans [3]. Thus, it is an emerging issue in environmental science and engineering to achieve an effective removal of DOM from drinking water and wastewater sources.

In recent years, various advanced oxidation processes (AOPs) have been proposed for the removal of DOM [6-8] and organic pollutants [9-11]. Common approaches include UV-based irradiation, ozonation, heterogeneous photocatalysis, Fenton and photo/electro-Fenton processes, electrochemical oxidation, and ultrasound irradiation. Among the AOPs, heterogeneous photocatalysis has been demonstrated to be highly efficient, low-cost, environment-friendly, and sustainable technology for the DOM degradation and reducing the DBPs formation [12-19]. The mechanism of heterogeneous photocatalysis is based on the in-situ generation of highly reactive oxygen species (ROS) (e.g., ${ }^{\circ} \mathrm{OH}, \mathrm{O}_{2}^{--}$) which degrade organic pollutants into $\mathrm{CO}_{2}, \mathrm{H}_{2} \mathrm{O}$ and other inorganic substance by irradiat-
This is an Open Access article distributed under the terms of the Creative Commons Attribution Non-Commercial License (http://creativecommons.org/licenses/by-nc/3.0/) which permits unrestricted non-commercial use, distribution, and reproduction in any medium, provided the original work is properly cited.

Copyright (C) 2021 Korean Society of Environmental Engineers
Received April 24, 2020 Accepted July 05, 2020

${ }^{\dagger}$ Corresponding author

Email: namsn76@gmail.com

Tel: +82-2-826-4528 Fax: +82-2-826-4528

ORCID: 0000-0002-8664-5912 
ing semiconductor catalysts (e.g., $\mathrm{TiO}_{2}, \mathrm{ZnO}, \mathrm{WO}_{3}, \mathrm{Fe}_{2} \mathrm{O}_{3}, \mathrm{CdO}$, $\mathrm{CdS}, \mathrm{SnO}_{2}$, etc.) with a light source (e.g., ultraviolet (UV), visible, or solar light) [20-23]. Typically, the electron-hole pairs $\left(\mathrm{e}_{\mathrm{CB}}^{-} / \mathrm{h}_{\mathrm{VB}}^{+}\right)$ are generated by the light absorption of semiconductor photocatalyst [21-23]. Subsequently, the VB hole $\left(\mathrm{h}_{\mathrm{VB}}^{+}\right.$) reacts with $\mathrm{H}_{2} \mathrm{O}$ and $\mathrm{OH}^{-}$ to generating hydroxyl radicals $\left({ }^{\circ} \mathrm{OH}\right)$, while the $\mathrm{CB}$ electrons $\left(\mathrm{e}_{\mathrm{CB}}^{-}\right)$ reacts with $\mathrm{O}_{2}$ to generating superoxide radicals $\left(\mathrm{O}_{2}^{--}\right)$[23-26]. These ROSs have strong oxidizing power to degrade many organic pollutants $[22,26]$. In this approach, there are three pathways for DOM degradation, namely, oxidation by hydroxyl radicals, reduction by superoxide radicals, and adsorption by catalyst [6-8]. The efficiency of the photocatalytic processes is highly dependent on the light source and semiconductor catalysts. According to recent researches [13-17, 27-29], the majority of DOM photodegradation methods use UV light coupled with different catalysts (e.g., $\mathrm{TiO}_{2}, \mathrm{ZnO}$ ). However, the amount of UV radiation in sunlight is limited (only 5-7\%), greatly restricting practical application of the UV photocatalytic oxidation technology. Sunlight, a renewable, abundant, non-polluting, and cheap energy source [21, 26], can be used as a low-cost and sustainable replacement for UV light in the photocatalysis. Additionally, sunlight irradiation has been noted to change the characteristics on DOM [30,31]. Thus, it is of great interest to use the solar/visible light as a light source in the photocatalytic degradation of DOM.

Though a few studies have focused on the degradation of DOM via solar photocatalysis using $\mathrm{TiO}_{2}$ and modified-TiO ${ }_{2}[18,19]$, little research on visible/solar photocatalysis assisted by $\mathrm{ZnO}$ has been reported to date in our knowledge. $\mathrm{ZnO}$, with its low-cost, non-toxicity, strong oxidation ability, and broad absorption range in the solar spectrum, can be a more efficient catalyst candidate than $\mathrm{TiO}_{2}$ in the photocatalysis [22, 26]. Therefore, this study proposes a visible/solar photocatalytic process using $\mathrm{ZnO}$ for the degradation of DOM.

Dissolved organic carbon (DOC), ultraviolet/visible (UV/Vis) and fluorescence spectroscopy are commonly used analytical methods in DOM analyses. DOC provides information on the quantity of DOM in terms of organic carbon while UV/Vis spectroscopy shows the characteristics of DOM such as the aromaticity, molecular weight, hydrophobicity and hydrophilicity [32, 33]. Fluorescence spectroscopy, a non-destructive and highly sensitive optical technique, is commonly used for rapidly assessing DOM levels in aquatic environments [34]. Fluorescence EEM-PARAFAC technique is useful in tracking various DOM substances [33, 34]. The peak locations or intensities of individual PARAFAC constituents can be used to evaluate the water quality and treatment performance [34]. Recently, the EEM-PARAFAC was applied for tracing fluorescent DOM components in $\mathrm{UV} / \mathrm{TiO}_{2}$ photocatalytic processes [13-15] and provided mechanistic understanding on transformation of DOM by the processes. However, to date, only few studies used EEM-PARAFAC to assess the photocatalytic degradation mechanism of DOM under ZnO-catalyzed sunlight irradiation system [15]. Therefore, a combination of traditional assessment parameters (e.g. DOC and UV parameters) and EEM-PARAFAC analysis is employed in this study to trace and provide further insight into the solar photocatalytic degradation of DOM using ZnO.

The degradation efficiency of organic pollutants is strongly dependent on several operating parameters, including dosage, size, and structure of catalyst, $\mathrm{pH}$ level, irradiation time, light intensity, temperature, and scavengers, etc. [12, 23, 35-39]. To investigate their effects on the photodegradation of DOM, response surface methodology (RSM), a widely used technique for analyzing and modeling experimental processes [29, 40, 41], was applied. We used central composite design (CCD) to generate necessary experimental runs. Therefore, the RSM-CCD was applied for assessment the effect of varying operating parameters and identifying the optimal conditions for the photocatalysis of DOM with $\mathrm{ZnO}$ under artificial sunlight irradiation.

In summary, this study aims at:

1) understanding of degradation mechanism by tracking water quality parameters and individual fluorescing components of DOM using EEM-PARAFAC modeling

2) assessing the photocatalytic degradation of DOM, including kinetics and effects of different operating conditions $(\mathrm{ZnO}$ dosage and $\mathrm{pH}$ ) under $\mathrm{ZnO}$-assisted simulated sunlight system finding the optimal operating conditions for the photodegradation of DOM using RSM-CCD.

\section{Experimental Methods}

\subsection{Chemicals and Reagents}

Humic acid (HA) used as a representative chemical of DOM and Zinc oxide (ZnO, MW: $81.39 \mathrm{~g} / \mathrm{mol}$, purity $\geq 99 \%$ ) were purchased from Sigma-Aldrich (USA). Sodium hydroxide $(\mathrm{NaOH}$, purity $\geq$ 93\%) was obtained from Daejung Chemicals (South Korea). Sulfuric acid $\left(\mathrm{H}_{2} \mathrm{SO}_{4}\right.$, purity $\left.\geq 96 \%\right)$ was purchased from Kanto Chemicals (Japan). By dissolving the HA in de-ionized water (DI water; $\geq$ $18.2 \Omega \cdot \mathrm{cm}^{-1}$ ) and filtering it through a $0.45-\mu \mathrm{m}$ hydrophilic polytetrafluoroethylene (PTFE) membrane, a stock DOM solution with a concentration of DOC $=10 \mathrm{mg} / \mathrm{L}$. Other solutions were prepared using DI water and diluted as required.

\subsection{Photocatalytic Experiments}

The photocatalytic experiments were performed by a solar simulator (SLB300B, Sciencetech, Canada) equipped with a $300 \mathrm{~W}$ xenon short arc lamp (Ushio Inc., Japan) emitting a visible light with a wavelength range of 350-2,000 nm (Fig. S1). The radiant flux on the surface of samples was measured to $3.15 \pm 0.05 \mathrm{~mW} / \mathrm{cm}^{2}$ by a radiation intensity meter (UV-340C, Custom, Tokyo, Japan), which values were in similar levels to natural sunlight's intensities that were monitored during the experimental periods. The distance between the solution and the light source was maintained at $\sim 5$ $\mathrm{cm}$. While being gently stirred for uniform mixing, the 100-mL samples in a Pyrex reactor with water jacket were irradiated for $180 \mathrm{~min}$ at room temperature $\left(23 \pm 1^{\circ} \mathrm{C}\right)$ (Fig. S2).

Three initial $\mathrm{pH}$ levels of the solution (i.e., $\mathrm{pH} \mathrm{4,} \mathrm{7,} \mathrm{and} \mathrm{10)}$ were generated by adjusting the solution with $1 \mathrm{M} \mathrm{H}_{2} \mathrm{SO}_{4}$ and $1 \mathrm{M}$ $\mathrm{NaOH}$. ZnO dosages were considered in $0.1,0.2$, and $0.3 \mathrm{~g} / \mathrm{L}$. At regular time intervals $(0,30,60,120$ and $180 \mathrm{~min})$, samples were taken and immediately filtered through $0.45-\mu \mathrm{m}$ PTFE syringe filters to separate the $\mathrm{ZnO}$ powder from the solution.

\subsection{Analytical Methods}

DOC was determined using a TOC- $\mathrm{V}_{\mathrm{CPH}}$ analyzer (Shimadzu, Japan). 
UV/Vis spectra were recorded at a wavelength range of 200-800 nm using UV spectrophotometer (SPECORD 200 PLUS, Analytik Jena AG, Germany) with a 1-cm quartz cuvette. The single wavelength parameters such as $\mathrm{UV}_{254}, \mathrm{UV}_{280}, \mathrm{UV}_{365}$, and Color $436\left(\mathrm{UV}_{436}\right)$, and the specific UV absorbance parameters SUVA $254, \mathrm{SUVA}_{280}, \mathrm{SUVA}_{365}$, and $\mathrm{SCOA}_{436}$; were determined from UV/Vis spectrum to monitor the changes of DOM during photocatalysis (Table S2).

A Cary Eclipse fluorescence spectrophotometer (Agilent Technologies, Inc, USA) was used to create the EEM fluorescence spectra by scanning the samples over an excitation range of 230-450 $\mathrm{nm}$ and over an emission range of $260-550 \mathrm{~nm}$, both in 1-nm increments. The excitation and emission bandwidths were set as $10 \mathrm{~nm}$, and the scanning speed was set as $9600 \mathrm{~nm} / \mathrm{min}$. To limit second-order Rayleigh scattering, we used a 290-nm cutoff for the samples. To minimize the inner filter effect, we diluted the samples, approximately to DOC $=1 \mathrm{mgC} / \mathrm{L}$, before EEM measurements. The EEMs of the samples were subtracted from a water blank measured on the same day as the samples. The EEMs were further normalized by dividing them by a Raman peak area of $370-700 \mathrm{~nm}$.

The morphological and crystalline characteristics of $\mathrm{ZnO}$ were observed by FE-SEM and XRD, as shown in Fig. S3. The FE-SEM image of $\mathrm{ZnO}$ shows its typical hexagonalprism morphology. XRD diffractogram of $\mathrm{ZnO}$ used in this study is exactly matched to the hexagonal wurtzite structure of $\mathrm{ZnO}$ ( $\mathrm{P}_{3} \mathrm{mc}$ (\#186), ICDD No. 96-901-1663), and the characteristic peaks are observed at $31.78^{\circ}$, $34.46^{\circ}, 36.27^{\circ}, 47.57^{\circ}, 56.64^{\circ}, 62.90^{\circ}, 66.42^{\circ}, 67.96^{\circ}, 69.10^{\circ}$ and $76.98^{\circ}$ corresponding to (100), (002), (101), (012), (110), (013), (200), (112), (201) and (202) planes, respectively. The cell parameters of $\mathrm{ZnO}$ were determined to be $\mathrm{a}=\mathrm{b}=3.2512 \AA$, $\mathrm{c}=5.2051$ $\AA, \mathrm{c} / \mathrm{a}=1.60, \alpha=90.00^{\circ}, \beta=90.00^{\circ}$, and $\gamma=120.00^{\circ}$, which are in good agreement with the standard values $\left[\mathrm{P6}_{3} \mathrm{mc}\right.$ (\#186) with $\mathrm{a}=\mathrm{b}=3.2490 \AA, \mathrm{c}=5.2070 \AA, \mathrm{c} / \mathrm{a}=1.60, \alpha=90.00^{\circ}$, $\beta=90.00^{\circ}$, and $\gamma=120.00^{\circ}$. The crystallite size of $\mathrm{ZnO}$ was determined by the Scherer's formula [42] using (101) peaks in the XRD patterns. The average crystallite size calculated for $\mathrm{ZnO}$ was $71.36 \mathrm{~nm}$.

\subsection{PARAFAC Modeling}

PARAFAC was used to extract the components from the dataset of EEMs. Under PARAFAC analysis, the EEM dataset is decomposed into a set of trilinear terms (F) and a residual array. The underlying EEM spectra are estimated by minimizing the sum of the squared residuals of the trilinear model as follows [27, 34]:

$$
x_{i j k}=\sum_{f=1}^{F} a_{i f} b_{j f} c_{k f}+\varepsilon_{i j k}, \quad i=1, \ldots, I ; j=1, \ldots, J ; k=1, \ldots, K_{(1)}
$$

where $x_{i j k}$ is the fluorescence intensity for the $i_{t h}$ sample at emission wavelength $j$ and excitation wavelength $k$, $a_{i f}$ is directly proportional to the concentration of the $f_{\text {th }}$ fluorophore in the $i_{\text {th }}$ sample (defined as scores), and $b_{j f}$ and $c_{k f}$ are the estimates of the emission and excitation spectra, respectively, for the $f_{\text {th }}$ fluorophore. $F$ represents the number of components in the model, and $\varepsilon_{i j k}$ is the residual variability not accounted for by the model.

PARAFAC modeling was performed using MATLAB 7.0 (Mathworks, MA, USA) with the DOMFluor Toolbox (http://www. models.life.ku.dk). The maximum fluorescence intensity $\left(\mathrm{F}_{\max }\right)$ values of the individual components were used to represent their relative concentrations. The degradation efficiency of DOM in terms of individual components is calculated using $\mathrm{F}_{\max }$ value. The determination and validation of components in the model were performed using split-half validation, explained variation ( $>99.9 \%$ ), core consistency diagnostic ( $>85 \%$ ), Tucker's congruence coefficient, and the spectral analysis of the excitation and emission loadings. The EEM data for the PARAFAC model were obtained based on 125 EEM data. Details of the PARAFAC can be found in other studies [13-15, 34].

\subsection{Design of Experiment}

This subsection describes the design process of experiments to investigate the degradation efficiency of DOM under solar photocatalysis. First, two main experimental factors, denoted as A for $\mathrm{ZnO}$ dosage $(\mathrm{g} / \mathrm{L})$ and $\mathrm{B}$ for $\mathrm{pH}$, were selected as the independent variables. The range and levels of each independent variable are given in Table 1. The degradation efficiency of DOM in terms of DOC, $\mathrm{UV}_{254}$, and PARAFAC components was used as response functions (Y). Second, using statistical software (Minitab Ver.18., State College, PA), a two-factor-three-level CCD with 13 experimental runs was designed. These experimental runs included a complete factorial design with $\left(2^{\mathrm{n}}\right)$ experiments, 4-star points, and 5 central points. Third, after we obtained the results, the experimental data were fitted to the second-order (quadratic) polynomial models, which had a common expression as follows [21, 29, 41]:

$$
\mathrm{Y}=b_{0}+b_{1} \mathrm{~A}+b_{2} \mathrm{~B}+b_{12} \mathrm{AB}+b_{11} \mathrm{~A}^{2}+b_{22} \mathrm{~B}^{2}
$$

where $Y$ is the response function, $A$ and $B$ are independent parameters, $b_{0}$ is the model constant, $b_{1}$ and $b_{2}$ are the linear coefficients, $b_{12}$ is the interaction coefficients, and $b_{11}$ and $b_{22}$ are the quadratic coefficients.

An analysis of variance (ANOVA) was employed to test and produce response surface graphs from the experimental data. The quality and goodness-of-fit of the models were evaluated using the F-values, $p$-values, coefficients of determination $\left(\mathrm{R}^{2}\right)$, adjusted $R^{2}$, and predicted $R^{2}$. The quantitative effects of the independent variables were determined based on the ANOVA results (F-values and $p$-values). Percentage contributions (PCs) for each individual

\begin{tabular}{|c|c|c|c|c|c|c|}
\hline \multirow{2}{*}{ Experimental parameters } & \multirow{2}{*}{ Symbol Coded } & \multicolumn{3}{|c|}{ Levels } & \multicolumn{2}{|c|}{ Star point $\alpha=1.414$} \\
\hline & & -1 & $\mathbf{0}$ & 1 & $+\alpha$ & $-\alpha$ \\
\hline $\mathrm{ZnO}$ dosage (g/L) & A & 0.1 & 0.2 & 0.3 & 0.34 & 0.06 \\
\hline $\mathrm{pH}$ & $\mathrm{B}$ & 4 & 7 & 10 & 11.24 & 2.76 \\
\hline
\end{tabular}

Table 1. Experimental Ranges and Levels of the Independent Operating Variables for RSM-CCD Experimental Design 
variable were calculated as [21, 41]:

$$
\begin{aligned}
& \mathrm{TPC}_{\mathrm{i}}=\frac{\sum_{\mathrm{i}=1}^{\mathrm{n}} \mathrm{SS}_{\mathrm{i}}}{\sum_{\mathrm{i}=1}^{\mathrm{n}} \sum_{\mathrm{j}=1}^{\mathrm{n}} S \mathrm{SS}_{\mathrm{i}}+\mathrm{SS}_{\mathrm{ii}}+\mathrm{SS}_{\mathrm{ij}}} \times 100 \\
& \mathrm{TPC}_{\mathrm{ij}}=\frac{\sum_{\mathrm{i}=1}^{\mathrm{n}} \sum_{\mathrm{j}=1}^{\mathrm{n}} \mathrm{SS}_{\mathrm{ij}}}{\sum_{\mathrm{i}=1}^{\mathrm{n}} \sum_{\mathrm{j}=1}^{\mathrm{n}} \mathrm{SS}_{\mathrm{i}}+\mathrm{SS}_{\mathrm{ii}}+\mathrm{SS}_{\mathrm{ij}}} \times 100 \\
& \mathrm{TPC}_{\mathrm{ii}}=\frac{\sum_{\mathrm{i}=1}^{\mathrm{n}} \sum_{\mathrm{i}=1}^{\mathrm{n}} \mathrm{S} \mathrm{S}_{\mathrm{ii}}}{\sum_{\mathrm{i}=1}^{\mathrm{n}} \sum_{\mathrm{j}=1}^{\mathrm{n}} S S_{\mathrm{i}}+S S_{\mathrm{ii}}+S S_{\mathrm{ij}}} \times 100
\end{aligned}
$$

where $T P C_{i}$, $T P C_{i j}$, and $T P C_{i i}$ are the total percentage contribution of the first-order, interaction, and quadratic terms, respectively, and $S S_{i}, S S_{i j}$, and $S S_{i i}$ are the computed sum of squares for the first-order, interaction, and quadratic terms, respectively. Finally, the optimal conditions to maximize the DOM degradation were determined from the multiple responses fitted RSMs.

\section{Results and Discussion}

\subsection{Characterization of DOM}

The UV/Vis spectra of the DOM are depicted in Fig. S4 (a). There was a decrease in the absorbance as the wavelength increased. The spectra showed a strong absorbance in the UV/Vis range (200$800 \mathrm{~nm}$ ), particularly in the UV region with no extrema, indicating that the DOM contained a relatively high amount of aromatic or polyphenolic organic compounds [8, 16]. Furthermore, SUVA 254 values were higher than $4\left(\mathrm{SUVA}_{254}=4.52 \pm 0.13(\mathrm{~L} / \mathrm{mg} \cdot \mathrm{m})\right)$, revealing that the DOM mainly contained hydrophobic and aromatic compounds [16-18]. These observations demonstrated that the DOM was primarily composed of hydrophobic compounds with high molecular weights (HMWs).

The EEM fluorescence spectroscopy was used to explore the position of fluorescence peaks to identify the source and composition of DOM. The EEM of the DOM (Fig. S4 (b)) showed that there were broad and strong peaks at emission wavelengths above $\sim 350 \mathrm{~nm}$, commonly referred to as humic-like peak [16-18, 34]. The EEM-PARAFAC analysis successfully decomposed fluorescent DOM into two components ( $\mathrm{C} 1$ and $\mathrm{C} 2$ ), which were identified as terrestrial humic-like organic matters (Fig.S5 and Table S3). Based on the $\mathrm{F}_{\max }$ values of PARAFAC components, C1 (58\%) was more dominant than C2 (42\%). As shown in Fig.S5, C1 had a peak at an Ex/Em of $261 \mathrm{~nm} / \geq 500 \mathrm{~nm}$, exhibiting a broad excitation spectrum and gradual emission above $350 \mathrm{~nm}$. C1 represented a combination of peak $\mathrm{A}$ and peak $\mathrm{C}$, implying that $\mathrm{C} 1$ is expected to absorb light in the UVC and UVA (wavelengths greater than
$320 \mathrm{~nm}$ ) regions [17, 27, 34]. Meanwhile, C2 had a peak at an $\mathrm{Ex} / \mathrm{Em}$ of $<230 \mathrm{~nm} / 438 \mathrm{~nm}$, with a shoulder peak at an excitation range of $300-350 \mathrm{~nm}$. C2 appeared to be a peak A, implying that C2 was easily photodegraded by UVC light, as the peak excitation wavelength for this component occurred in this region of light $[17,34]$. The $\mathrm{C} 2$ peak, compared to that of C1, was likely to be blue-shifted in both excitation and emission spectra, which would indicate that $\mathrm{C} 1$ had a higher molecular weight and was more hydrophobic than $\mathrm{C} 2$.

Additionally, the chemical characteristics of the DOM (i.e., Sigma-Aldrich HAs) have been reported in the literatures [4, 5, 8]. The elemental composition of HAs are approximately $55.6-68.98 \% \mathrm{C}, 5.26-5.5 \% \mathrm{H}, 0.74-4.5 \% \mathrm{~N}, 1.2-4.24 \% \mathrm{~S}$, and $34.4-43.45 \%$ O. The HAs are mainly composed of phenolic, carboxylic acid, enolic, quinone, and other functional groups. The carboxylic $\left(4.38 \pm 0.03 \mathrm{meq} \cdot \mathrm{g}^{-1} \mathrm{C}\right)$ and phenolic $\left(2.71 \pm 0.34 \mathrm{meq} \cdot \mathrm{g}^{-1} \mathrm{C}\right)$ groups are the main functional groups, while the quinones are responsible for the formation of reactive oxygen species in HAs.

\subsection{Photocatalytic Degradation of DOM}

\subsubsection{UV/Vis spectroscopic analysis}

Fig. S6 (a) illustrates the UV/Vis spectrum for the DOM during the photocatalysis process with $0.2 \mathrm{~g} / \mathrm{L}$ of $\mathrm{ZnO}$ dosage at $\mathrm{pH} 7$. The absorbance decreased as the reaction time increased; moreover, there was a rapid reduction in the absorbance for the photocatalysis with $\mathrm{ZnO}$ in suspension. The UV/Vis absorption remained constant after 180 min of irradiation, indicating that complete mineralization could not be achieved. The UV parameters were determined and given in Table 2 .

There was a rapid reduction in all single wavelength absorbance in the order of Color ${ }_{436}>\mathrm{UV}_{365}>\mathrm{UV}_{280}>\mathrm{UV}_{254}$, as expressed in Fig. S6 (b). The $\mathrm{UV}_{254}$ values showed that the DOM chromophores, mostly consisting of large aromatic rings, might have been rapidly decomposed into smaller non-aromatic structures [13-17]. As shown in Table 2, both UV absorbance ratios of treated DOM continuously increased during the photocatalysis process. The $A_{250} / A_{365}$ ratio implied a decrease in the aromaticity and molecular weight, while the $\mathrm{A}_{254} / \mathrm{A}_{436}$ ratio implied a high removal rate of color-forming moieties [16, 17]. Additionally, a reduction in the molecular weight was also observed based on the increase of slope ratio $\left(S_{R}\right)$ during the process [16, 17].

Fig. S6 (c) shows the SUVA values of DOM during the photocatalysis process. We observed a considerable decrease in all SUVA values, implying a reduction in aromatic halogen attack sites, a decrease in the molecular size, and an elimination of quinones [14-17]. Specifically, there was a substantial reduction in $\mathrm{SUVA}_{254}$

Table 2. UV/Vis Parameters of DOM During Solar Photocatalytic Degradation Process with $0.2 \mathrm{~g} / \mathrm{L} \mathrm{ZnO}$ Dosage at $\mathrm{pH} 7$

\begin{tabular}{lccccccccccc}
\hline Time (min) & $\mathbf{U V}_{\mathbf{2 5 4}}$ & $\mathbf{U V}_{\mathbf{2 8 0}}$ & $\mathbf{U V}_{\mathbf{3 6 5}}$ & $\mathbf{C o l o r}_{\mathbf{4 3 6}}$ & $\mathbf{S U V A}_{\mathbf{2 5 4}}$ & $\mathbf{S U V A}_{\mathbf{2 8 0}}$ & $\mathbf{S U V A}_{\mathbf{3 6 5}}$ & $\mathbf{S U V A}_{\mathbf{4 3 6}}$ & $\mathbf{A}_{\mathbf{2 5 0}} / \mathbf{A}_{\mathbf{3 6 5}}$ & $\mathbf{A}_{\mathbf{2 5 4}} / \mathbf{A}_{\mathbf{4 3 6}}$ & $\mathbf{S}_{\mathbf{R}}$ \\
\hline 0 & 0.5520 & 0.4525 & 0.1721 & 0.0781 & 4.63 & 3.80 & 1.44 & 0.66 & 3.27 & 7.07 & 0.86 \\
30 & 0.3814 & 0.2933 & 0.1102 & 0.0484 & 3.45 & 2.65 & 1.00 & 0.44 & 3.55 & 7.88 & 1.07 \\
60 & 0.2462 & 0.1783 & 0.0648 & 0.0258 & 2.44 & 1.76 & 0.64 & 0.26 & 3.91 & 9.54 & 1.27 \\
120 & 0.0537 & 0.0231 & 0.0052 & 0.0011 & 0.62 & 0.27 & 0.06 & 0.01 & 10.85 & 48.82 & 3.26 \\
180 & 0.0246 & 0.0079 & 0.0012 & 0.0001 & 0.36 & 0.12 & 0.02 & 0.00 & 22.58 & 246.00 & 10.00 \\
\hline Removal (\%) & 95.54 & 98.25 & 99.30 & 99.87 & 92.18 & 96.93 & 98.78 & 99.78 & & \\
\hline
\end{tabular}


(over 90\% of initial values) which could be explained by the preferential removal of aromatic chromophores over aliphatic moieties, followed by the transition of the DOM to non- or less-UV-absorbing substances. The reduction in $\mathrm{SUVA}_{254}$ also implied that HMW DOM was rapidly decomposed into organic compounds of lower molecular weight (LMW) [14-17]. This observation was supported by the lower DOC removal values compared to $\mathrm{UV}_{254}$ values at the same reaction time. Furthermore, a strong linear correlation was observed between $\mathrm{SUVA}_{254}$ and DOC $\left(\mathrm{R}^{2}=0.98\right)$, indicating that the decreases in $\mathrm{SUVA}_{254}$ could be used as indicators of DOC removal efficiency during the photocatalytic degradation of DOM.

\subsubsection{Fluorescence EEM}

Fig. S7 illustrates the EEM contour plots of DOM with $0.2 \mathrm{~g} / \mathrm{L}$ of $\mathrm{ZnO}$ dosage at $\mathrm{pH} 7$ during the photocatalysis process. The photocatalysis led to a continuous reduction in the fluorescence intensity and changes in the shape of the EEM plots. After 180-min irradiation, the fluorescence intensity for the measured wavelengths was almost zero, with no clear peak. The decreased fluorescence intensity in the EEM plots implied that the preferential photocatalytic degradation of DOM caused the breakdown of HMW fractions and the formation of LMW fractions [16-18]. This observation was similar to the previously reported photodegradation of DOM [16-19].

\subsubsection{Photocatalysis of DOM: kinetics and degradation efficiency}

The photocatalytic degradation efficiency of DOM was analyzed based on the removals of DOC, $\mathrm{UV}_{254}$, and $\mathrm{F}_{\max }$ values of the two PARAFAC components. Upon photocatalysis, all degradation rates were found to be a pseudo-first-order kinetic model $\left(\mathrm{R}^{2}=0.90-1.00\right)$, which had also been reported in other studies to describe the photodegradation of DOM [13-17, 27].

After 180-min treatment, the DOC removals varied from $19.18 \%$ to $62.61 \%$ while $\mathrm{UV}_{254}$ removals were in the range of $55.20 \%$ to 96.18\%. Overall, greater removal efficiencies of $\mathrm{UV}_{254}$ than DOC were found, and the reasons can be as the followings. First, the terminal functional groups (e.g., hydroxyl and carboxyl) of the aromatic compounds reinforced the adoption affinity of the surface of the catalyst particles [13-16]. Second, some of the DOM chromophores were partially transformed into non-UV-absorbing compounds (e.g., LMW organic acids, alcohols, etc.) in the photochemical reaction [14-17], thus those non-UV-absorbing moieties are responsible for DOC unremoved.

The photodegradation behaviors of the two PARAFAC components were analyzed using $\mathrm{F}_{\max }$ values. The degradation kinetics based on Fmax were fitted with a pseudo-first order kinetic model $\left(\mathrm{R}^{2}=0.94-0.99\right)$. After 180-min irradiation, the $\mathrm{C} 1$ removals varied from $67.61 \%$ to $100 \%$, and the highest removal was observed after 120-min irradiation at a $\mathrm{ZnO}$ dosage of $0.3 \mathrm{~g} / \mathrm{L}$ and $\mathrm{pH}$ 7. The $\mathrm{C} 2$ removals were found to be in $12.38 \%$ to $99.45 \%$.

$\mathrm{F}_{\max }$ removal and degradation rate of $\mathrm{C} 1$ were higher than those of $\mathrm{C} 2$, which could be explained by the excitation and emission wavelengths of each component. Both PARAFAC components were identified as terrestrial humic-like organic matters; however, C1 represented a combination of peak $\mathrm{A}$ and peak $\mathrm{C}$, showing longer excitation and emission wavelengths than C2. With peaks at longer wavelengths, C1 could be associated with the structural con- densation and polymerization of DOM [18, 34]. Indeed, previous researches reported more pronounced fluorescence at longer emission wavelengths in the EEMs of larger size and/or more hydrophobic DOM fractions [13-19]. Therefore, the results indicated the preferential adsorption of more hydrophobic and larger DOM molecules onto minerals and/or nanoparticles, which has also been reported in previous studies [13-15]. In addition, C2 would be less excited by visible light than $\mathrm{C} 1$ due to shorter excitation wavelengths of C2 compared to that of C1.

Figure S8 shows the comparison of DOM removals and degradation rates calculated using DOC, $\mathrm{UV}_{254}$, and $\mathrm{F}_{\max }$ values of the PARAFAC components at $0.2 \mathrm{~g} / \mathrm{L} \mathrm{ZnO}$ and $\mathrm{pH}$ 7. The removals calculated using the $\mathrm{F}_{\max }$ of the two components (100\% for $\mathrm{C} 1$ and $98.42 \%$ for C2) were consistently higher than those calculated using $\mathrm{UV}_{254}$ (95.67\%) and DOC (43.52\%). The degradation rate of $\mathrm{C} 1$ was 11.31-fold and 8.46-fold higher than those calculated using DOC and $\mathrm{UV}_{254}$, while the degradation rate of $\mathrm{C} 2$ was 1.93-fold and 1.56-fold higher than those calculated using DOC and $\mathrm{UV}_{254}$, respectively. These results were supported by previous reports [1315] which demonstrated that fluorescent components were much more sensitive to UV light than other non-fluorescent structures. The higher degradation of fluorescence components compared to UV-absorbing moieties (i.e., $\mathrm{UV}_{254}$ ) could also be explained by the fluorescence arising from the $\pi^{*}-\pi$ transitions in DOM molecules and its quick elimination under UV irradiation [13-15].

\subsubsection{Effects of operational parameters}

Effect of $\mathrm{ZnO}$ dosage: The effects of $\mathrm{ZnO}$ dosages (0.1, 0.2, and $0.3 \mathrm{~g} / \mathrm{L})$ at $\mathrm{pH} 7$ on the degradation of DOM are depicted in Fig.1 (a) and (b). The DOM removal and apparent degradation rate ( $\left.k_{\text {app }}\right)$ increased considerably as the $\mathrm{ZnO}$ dosages increased from 0.1 $\mathrm{g} / \mathrm{L}$ to $0.3 \mathrm{~g} / \mathrm{L}$. Specifically, the DOM removal and $\mathrm{k}_{\text {app }}$ increased by $\Delta 29.61 \%$ and 2.52 -fold for DOC, by $\Delta 2.89 \%$ and 1.24 -fold for $\mathrm{UV}_{254}$, by $\Delta 4.46 \%$ and 173 -fold for $\mathrm{C} 1$, and by $\Delta 0.75 \%$ and 1.35-fold for C2. It could be because more active sites become available with increasing of $\mathrm{ZnO}$ dosage, and thus facilitating the ${ }^{\circ} \mathrm{OH}$ generation.

Effect of pH: The effects of $\mathrm{pH}(4,7$, and 10) on the degradation of $\mathrm{DOM}$ at $0.2 \mathrm{~g} / \mathrm{L}$ of $\mathrm{ZnO}$ are expressed in Fig. 1 (c) and (d). The DOM removal and $\mathrm{k}_{\text {app }}$ were in the order of $\mathrm{pH} 7>\mathrm{pH} 10$ $>\mathrm{pH}$ 4. This observation could be explained due to the ionization of $\mathrm{DOM}$ and the zeta potential (ZP) of $\mathrm{ZnO}$ at different $\mathrm{pH}$ levels. In particular, in HA molecules, the acidic functional groups (e.g., $-\mathrm{COOH}$ and $-\mathrm{OH}_{\text {phenolic }}$ ) would be more ionized as the aqueous $\mathrm{pH}$ increased because $\mathrm{pK}_{\mathrm{a},-\mathrm{COOH}}$ and $\mathrm{pK}_{\mathrm{a},-\mathrm{OH}}$ have been reported to be 4.7 and 12.5 , respectively $[4,5]$ :

$$
\text { HOOC } \cdots-\mathrm{HA}-\cdots \mathrm{OH} \rightarrow{ }^{-} \mathrm{OOC} \cdots-\mathrm{HA}-\cdots \mathrm{O}^{-}+2 \mathrm{H}^{+}
$$

HAs were negatively charged over a wide $\mathrm{pH}$ range (2.0-10.7). The $\mathrm{ZP}$ of $\mathrm{ZnO}$ was positive at a $\mathrm{pH}$ range of 6.7-9.3 and negative otherwise (the $\mathrm{pH}_{\mathrm{ZPC}}$ for $\mathrm{ZnO}$ is $9.0 \pm 0.3$ ), according to the following reactions $[22,26,43]$ :

$$
\begin{gathered}
\mathrm{Zn}-\mathrm{OH}+\mathrm{H}^{+} \rightarrow \mathrm{ZnOH}_{2}^{+} \quad\left(\mathrm{pH}<\mathrm{pH}_{\mathrm{ZPC}}\right) \\
\mathrm{Zn}-\mathrm{OH}+\mathrm{OH}^{-} \rightarrow \mathrm{ZnO}^{-}+\mathrm{H}_{2} \mathrm{O} \quad\left(\mathrm{pH}>\mathrm{pH}_{\mathrm{ZPC}}\right)
\end{gathered}
$$



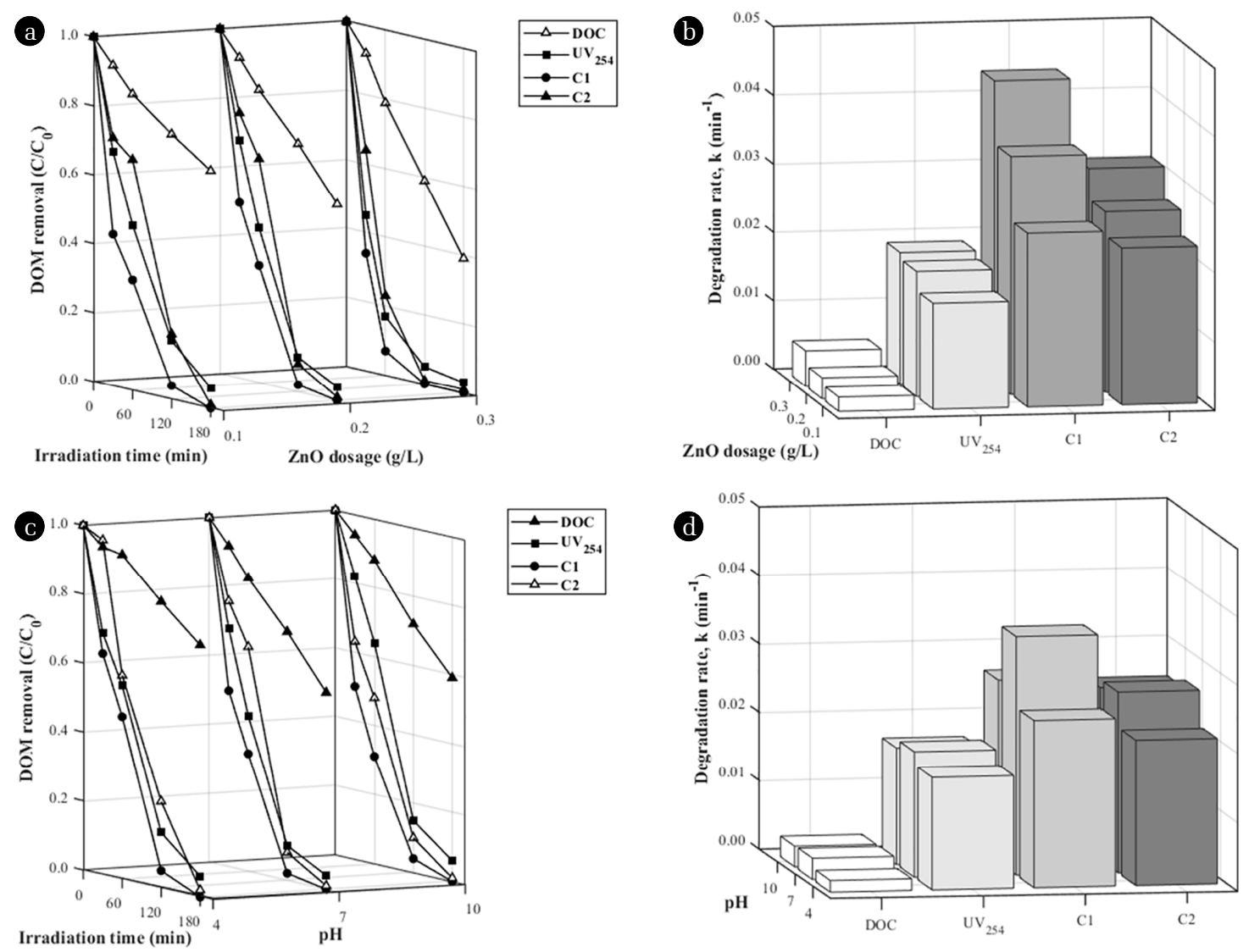

Fig. 1. Effects of $\mathrm{ZnO}$ dosage and $\mathrm{pH}$ on the photocatalytic degradation of DOM: Effect of $\mathrm{ZnO}$ dosage at $\mathrm{pH} 7$ - (a) DOM removal and (b) Degradation rate; Effect of $\mathrm{pH}$ at $\mathrm{ZnO} 0.2 \mathrm{~g} / \mathrm{L}$ - (c) DOM removal and (d) Degradation rate.

Therefore, at $\mathrm{pH}$ 7, ZnO and HA had opposing charges, and the electrostatic attraction between HA molecules and the $\mathrm{ZnO}$ surface would lead to a more rapid exposure of the HAs to reactive oxygen species (especially ${ }^{\circ} \mathrm{OH}$ ), resulting in the maximum DOM removal and $\mathrm{k}_{\mathrm{app}}$. On the other hand, at $\mathrm{pH} 4$ and 10, both the HAs and $\mathrm{ZnO}$ were negatively charged, thus there would be a strong repulsive force between the $\mathrm{HA}$ molecules and the $\mathrm{ZnO}$ surface. Consequently, there would be limited chances for the HA molecules to contact with reactive oxygen species near the $\mathrm{ZnO}$ surface, decreasing removal and $\mathrm{k}_{\mathrm{app}}$.

In addition, the DOM removal and $k_{\text {app }}$ were always higher at $\mathrm{pH} 10$ than those at $\mathrm{pH}$ 4. This observation could be explained by two reasons. First, it has been reported that $\mathrm{ZnO}$ can be photo-oxidized at $\mathrm{pH} 4$ (acidic conditions), as given in Eq. (9) [22, 44]. Meanwhile, $\mathrm{ZnO}$ can be dissolution to $\mathrm{Zn}(\mathrm{OH})_{4}^{2-}$ at $\mathrm{pH} 10$ (alkaline conditions), as given in Eq. (10) [22, 44]. The dissolution of $\mathrm{ZnO}$ into $\mathrm{Zn}^{2+}$ and $\mathrm{Zn}(\mathrm{OH})_{4}^{2-}$ would slow the mass transport rate and consequently reduce the active surface area of $\mathrm{ZnO}$. Second, acidic conditions (i.e., less $\mathrm{OH}^{-}$) were less favorable for the generation of ${ }^{\circ} \mathrm{OH}$ by the hole oxidation of $\mathrm{OH}^{-}$, lowering the efficiency of the attack of hydroxyl radicals on DOM and the photocatalytic oxidation rate [21, 27].

$$
\mathrm{ZnO}+2 \mathrm{H}^{+} \rightarrow \mathrm{Zn}^{2+}+\mathrm{H}_{2} \mathrm{O}
$$

$$
\mathrm{ZnO}+2 \mathrm{OH}^{-}+\mathrm{H}_{2} \mathrm{O} \rightarrow \mathrm{Zn}(\mathrm{OH})_{4}^{2-}
$$

\subsection{Optimization of DOM Degradation Using RSM Based on CCD}

In the present study, a two-factor-three-level CCD consisting of 13 experimental runs was employed to optimize the photocatalytic degradation efficiency of DOM. Four predicted responses - Y1 (DOC removal), Y2 ( $\mathrm{UV}_{254}$ removal), Y3 (C1 removal), and Y4 (C2 removal) - were expressed as second-order polynomial equations of two independent variables, $\mathrm{A}(\mathrm{ZnO}$ dosage) and $\mathrm{B}(\mathrm{pH})$, which are provided in Eqs.(11)-(14). The predicted and experimental values of the four responses with two independent variables are summarized in Table 3 .

$$
\begin{aligned}
& \mathrm{Y} 1(\mathrm{DOC} \text { removal })=-23.85+156.1 \mathrm{~A}+8.98 \mathrm{~B}- \\
& 135.7 \mathrm{~A}^{2}-0.5826 \mathrm{~B}^{2}+5.18 \mathrm{AB} \\
& \begin{array}{c}
\mathrm{Y} 2\left(\mathrm{UV}_{254} \text { removal }\right)=-42.19+519.8 \mathrm{~A}+18.73 \mathrm{~B}- \\
700.0 \mathrm{~A}^{2}-0.946 \mathrm{~B}^{2}-16.32 \mathrm{AB}
\end{array} \\
& \mathrm{Y} 3(\mathrm{C} 1 \text { removal })=-9.90+337.3 \mathrm{~A}+16.85 \mathrm{~B}- \\
& 425 \mathrm{~A}^{2}-0.875 \mathrm{~B}^{2}-11.23 \mathrm{AB} \\
& \mathrm{Y} 4(\mathrm{C} 2 \text { removal })=-207.6+918 \mathrm{~A}+47.85 \mathrm{~B}- \\
& 954 \mathrm{~A}^{2}-2.258 \mathrm{~B}^{2}-45.50 \mathrm{AB}
\end{aligned}
$$


Table 3. Two-Factors-Three-Level Central Composite Design for The Photocatalytic Degradation of DOM

\begin{tabular}{|c|c|c|c|c|c|c|c|c|c|c|}
\hline \multirow{3}{*}{ Exp. } & \multirow{3}{*}{$\frac{\mathrm{ZnO} \text { dosage }(\mathrm{g} / \mathrm{L})}{\mathrm{A}}$} & \multirow{3}{*}{$\begin{array}{c}\text { pH } \\
\text { B }\end{array}$} & \multicolumn{8}{|c|}{ Predicted response models (Y) (\%) } \\
\hline & & & \multicolumn{2}{|c|}{ Y1 (DOC removal) } & \multicolumn{2}{|c|}{ Y2 (UV ${ }_{254}$ removal) } & \multicolumn{2}{|c|}{ Y3 (C1 removal) } & \multicolumn{2}{|c|}{ Y4 (C2 removal) } \\
\hline & & & Experimental & Predicted & Experimental & Predicted & Experimental & Predicted & Experimental & Predicted \\
\hline 1 & 0.10 & 10.00 & 28.50 & 27.14 & 76.19 & 79.16 & 85.22 & 89.46 & 74.44 & 81.74 \\
\hline 2 & 0.20 & 7.00 & 43.04 & 43.52 & 95.54 & 95.67 & 100.00 & 100.00 & 98.97 & 98.37 \\
\hline 3 & 0.30 & 10.00 & 56.11 & 57.86 & 95.79 & 94.49 & 100.00 & 100.46 & 99.36 & 97.99 \\
\hline 4 & 0.20 & 7.00 & 43.85 & 43.52 & 95.87 & 95.67 & 100.00 & 100.00 & 97.97 & 98.37 \\
\hline 5 & 0.20 & 7.00 & 43.81 & 43.52 & 95.84 & 95.67 & 100.00 & 100.00 & 97.93 & 98.37 \\
\hline 6 & 0.20 & 11.24 & 41.17 & 40.93 & 89.34 & 88.07 & 98.17 & 94.28 & 94.01 & 87.93 \\
\hline 7 & 0.20 & 7.00 & 43.09 & 43.52 & 95.34 & 95.67 & 100.00 & 100.00 & 98.77 & 98.37 \\
\hline 8 & 0.34 & 7.00 & 62.61 & 60.33 & 96.18 & 99.44 & 100.00 & 104.04 & 99.45 & 110.11 \\
\hline 9 & 0.20 & 2.76 & 25.07 & 25.13 & 67.48 & 69.22 & 67.61 & 74.23 & 12.38 & 27.51 \\
\hline 10 & 0.30 & 4.00 & 42.04 & 43.58 & 94.39 & 90.95 & 100.00 & 93.02 & 98.96 & 82.60 \\
\hline 11 & 0.06 & 7.00 & 19.18 & 21.28 & 66.70 & 63.91 & 80.26 & 78.96 & 50.08 & 48.48 \\
\hline 12 & 0.20 & 7.00 & 43.78 & 43.52 & 95.77 & 95.67 & 100.00 & 100.00 & 98.22 & 98.37 \\
\hline 13 & 0.10 & 4.00 & 20.64 & 19.08 & 55.20 & 56.04 & 71.75 & 68.55 & 19.39 & 11.70 \\
\hline
\end{tabular}

Table 4. ANOVA Results of The Response Surface Quadratic Models for The DOM Removal (\%) in Terms of DOC, UV $254, \mathrm{C} 1$, and C2 Removal (\%)

\begin{tabular}{|c|c|c|c|c|c|}
\hline Source & Sum of squares & Degree of freedom & Mean square & F-value & p-value \\
\hline \multicolumn{6}{|c|}{ Y1, DOC removal } \\
\hline Model & 1978.49 & 5 & 395.7 & 137.830 & 0.000 \\
\hline Residual & 20.1 & 7 & 2.87 & & \\
\hline Lack of fit & 19.41 & 3 & 6.47 & 38.02 & 0.002 \\
\hline Pure error & 0.68 & 4 & 0.17 & & \\
\hline Total & 1998.59 & 12 & & & \\
\hline \multicolumn{6}{|c|}{$R^{2}=0.9899$, Adjusted $R^{2}=0.9828$, Predicted $R^{2}=0.9304$} \\
\hline \multicolumn{6}{|c|}{ Y2, $\mathrm{UV}_{254}$ removal } \\
\hline Model & 2462.9 & 5 & 492.58 & 74.61 & 0.000 \\
\hline Residual & 46.21 & 7 & 6.6 & & \\
\hline Lack of fit & 46.01 & 3 & 15.34 & 307.86 & 0.000 \\
\hline Pure error & 0.2 & 4 & 0.05 & & \\
\hline Total & 2509.11 & 12 & & & \\
\hline \multicolumn{6}{|c|}{$R^{2}=0.9816$, Adjusted $R^{2}=0.9684$, Predicted $R^{2}=0.8695$} \\
\hline \multicolumn{6}{|c|}{ Y3, C1 removal } \\
\hline Model & 1580.92 & 5 & 316.18 & 14.36 & 0.001 \\
\hline Residual & 154.14 & 7 & 22.02 & & \\
\hline Lack of fit & 154.14 & 3 & 51.38 & 14.36 & 0.001 \\
\hline Pure error & 0 & 4 & 0.00 & & \\
\hline Total & 1735.05 & 12 & & & \\
\hline \multicolumn{6}{|c|}{$R^{2}=0.9112$, Adjusted $R^{2}=0.8477$, Predicted $R^{2}=0.3683$} \\
\hline \multicolumn{6}{|c|}{ Y4, C2 removal } \\
\hline Model & 11404.10 & 5 & 2280.82 & 20.86 & 0.000 \\
\hline Residual & 765.30 & 7 & 109.33 & & \\
\hline Lack of fit & 764.40 & 3 & 254.80 & 1125.78 & 0.000 \\
\hline Pure error & 0.90 & 4 & 0.23 & & \\
\hline Total & 12169.40 & 12 & & & \\
\hline \multicolumn{6}{|c|}{$R^{2}=0.9371$, Adjusted $R^{2}=0.8922$, Predicted $R^{2}=0.5532$} \\
\hline
\end{tabular}

Two statistical measures (F-value and $p$-value) were used to evaluate the quality of the models. As shown in Table 4, the F-values of the four models $(\mathrm{Y} 1=137.83$, $\mathrm{Y} 2=74.61$, $\mathrm{Y} 3=14.36$ and $\mathrm{Y} 4=20.86)$ were greater than the $0.05 \mathrm{~F}$ critical value $\left(\mathrm{F}_{0.05,5,7}\right.$ = 3.97) [45], demonstrating the high statistical significance of the four regression models. Low $p$-values were also observed $(\leq 0.001$ for all models), further indicating the significance of these models. Thus, the four models explained the measured data well, with the corresponding coefficients demonstrating high significance.

$R^{2}$, adjusted $R^{2}$ and predicted $R^{2}$ were used to measure the 
degree of fit for the models. In this study, $\mathrm{R}^{2}$ values were $\mathrm{Y} 1=$ 0.9899 , Y2 $=0.9816$, Y3 $=0.9112$ and Y4 $=0.9371$, showing that the second-order polynomial models were reliably fitted to the experimental results. The $\mathrm{R}^{2}$ values of the four models were in the order of $\mathrm{Y} 1>\mathrm{Y} 2>\mathrm{Y} 4>\mathrm{Y} 3$. The highest $\mathrm{R}^{2}$ obtained for the model of DOC removal (Y1) indicated that $98.99 \%$ of the total variation could be represented by the established model, expressing a satisfactory quadratic fit. Adjusted $\mathrm{R}^{2}$ values were $\mathrm{Y} 1$ $=0.9828, \mathrm{Y} 2=0.9684, \mathrm{Y} 3=0.8477$ and $\mathrm{Y} 4=0.8922$, which were close to the $\mathrm{R}^{2}$ value for each model, and this indicates a good correlation among the factors of the process using the CCD design. Predicted $\mathrm{R}^{2}$ values were $\mathrm{Y} 1=0.9304$, $\mathrm{Y} 2=0.8695$, $\mathrm{Y} 3$ $=0.3683$ and $\mathrm{Y} 4=0.5532$, showing that the $\mathrm{Y} 1$ model was the best fitted among the models. The low values in predicted $\mathrm{R}^{2}$ for Y3 and Y4 (i.e., the removals of $\mathrm{C} 1$ and C2) are thought because there were remaining fractions of organic substances that do not respond to the light, but account for contents of organics as the more fluorescing DOMs are degraded to non-light absorbing organics.

In addition to the results of ANOVA and $\mathrm{R}^{2}$ values, diagnostic plots also confirmed a good agreement between the model prediction and the experimental data (Fig. S9). Therefore, the four regression models were statistically significant and could be used to predict the photodegradation of DOM.

The quantitative effects of each independent variable on DOM are summarized in Table 5. In the four models, all first-order terms
(A and B) were statistically significant ( $p$-values $<0.05)$. More specifically, in the Y1 model, the two first-order terms and one quadratic term $\left(\mathrm{B}^{2}\right)$ were statistically significant ( $p$-values $<0.05$ ). In the Y3 model, the two first-order terms and two quadratic terms $\left(A^{2}\right.$ and $\left.B^{2}\right)$ were statistically significant ( $p$-values $\left.<0.05\right)$. In the $\mathrm{Y} 2$ and the $\mathrm{Y} 4$ models, all terms $\left(\mathrm{A}, \mathrm{B}, \mathrm{A}^{2}, \mathrm{~B}^{2}\right.$, and $\left.\mathrm{AB}\right)$ were statistically significant ( $p$-values $<0.05$ ). Figure S10 illustrates the PCs of the variables in the four models. We observed the highest contribution (i.e., TPC) by the first-order terms (89.25\% for Y1, $63.22 \%$ for $\mathrm{Y} 2,63.12 \%$ for $\mathrm{Y} 3$, and $63.65 \%$ for $\mathrm{Y} 4)$. The quadratic terms were the second highest contributor $(10.26 \%$ for Y1, 32.03\% for Y2, 34.10\% for Y3, and 29.97\% for Y4). Moreover, ZnO dosage (A) showed the highest level of significance, with a contribution of $76.69 \%$ for Y1, 49.34 for Y2, 38.52 for Y3, and 32.46 for Y4.

Three-dimensional (3D) surfaces and two-dimensional (2D) contours of DOM degradation efficiency (\%) as predicted by four models (Y1, Y2, Y3 and Y4) are given in Fig. 2. Both ZnO dosage and $\mathrm{pH}$ had positive effects on DOM removal. The direct relationship between these two factors and the DOM degradation efficiency was also illustrated by the positive coefficients of A and B in all four models as expressed in Eqs. (10)-(13). Specifically, when the $\mathrm{ZnO}$ dosage increased from $0.1 \mathrm{~g} / \mathrm{L}$ to $0.3 \mathrm{~g} / \mathrm{L}$, DOM removal also increased by $24.50 \%$ for DOC, $34.91 \%$ for $\mathrm{UV}_{254}, 24.47 \%$ for $\mathrm{C} 1$, and $70.90 \%$ for $\mathrm{C} 2$ at $\mathrm{pH} 4$ compared to increases of $30.72 \%$ for DOC, $15.33 \%$ for $\mathrm{UV}_{254}, 11.00 \%$ for $\mathrm{C} 1$, and $16.25 \%$ for $\mathrm{C} 2$ at $\mathrm{pH}$ 10. The effect of $\mathrm{ZnO}$ dosage on the DOM degradation

Table 5. ANOVA Results for The Four Quadratic Models for DOM Photocatalytic Degradation

\begin{tabular}{|c|c|c|c|c|c|c|c|}
\hline Quadratic model & Factor & Coefficient & F-Value & p-Value & Sum of squares & Percentage contribution (\%) & Remark \\
\hline \multirow{6}{*}{$\begin{array}{l}\text { Y1 } \\
\text { (DOC removal) }\end{array}$} & Intercept & -23.85 & & & & & \\
\hline & A & 156.10 & 531.11 & 0.000 & 1524.7 & 76.69 & Significant \\
\hline & $\mathrm{B}$ & 8.98 & 86.97 & 0.000 & 249.7 & 12.56 & Significant \\
\hline & $A^{2}$ & -135.70 & 4.46 & 0.072 & 12.8 & 0.64 & No \\
\hline & $\mathrm{B}^{2}$ & -0.58 & 66.61 & 0.000 & 191.2 & 9.62 & Significant \\
\hline & $\mathrm{AB}$ & 5.18 & 3.36 & 0.109 & 9.7 & 0.49 & No \\
\hline \multirow{6}{*}{$\begin{array}{l}\mathrm{Y} 2 \\
\left(\mathrm{UV}_{254} \text { removal }\right)\end{array}$} & Intercept & -42.19 & & & & & \\
\hline & A & 519.80 & 191.18 & 0.000 & 1262.2 & 49.34 & Significant \\
\hline & $\mathrm{B}$ & 18.73 & 53.8 & 0.000 & 355.2 & 13.88 & Significant \\
\hline & $A^{2}$ & -700.00 & 51.62 & 0.000 & 340.8 & 13.32 & Significant \\
\hline & $\mathrm{B}^{2}$ & -0.95 & 76.38 & 0.000 & 504.3 & 19.71 & Significant \\
\hline & $\mathrm{AB}$ & -16.32 & 14.52 & 0.007 & 95.9 & 3.75 & Significant \\
\hline \multirow{6}{*}{$\begin{array}{l}\text { Y3 } \\
\text { (C1 removal) }\end{array}$} & Intercept & -9.90 & & & & & \\
\hline & A & 337.30 & 28.57 & 0.001 & 629.1 & 38.52 & Significant \\
\hline & $\mathrm{B}$ & 16.85 & 18.25 & 0.004 & 401.8 & 24.60 & Significant \\
\hline & $A^{2}$ & -425.00 & 5.71 & 0.048 & 125.7 & 7.70 & Significant \\
\hline & $\mathrm{B}^{2}$ & -0.88 & 19.58 & 0.003 & 431.2 & 26.40 & Significant \\
\hline & $\mathrm{AB}$ & -11.23 & 2.06 & 0.194 & 45.4 & 2.78 & No \\
\hline \multirow{6}{*}{$\begin{array}{l}\text { Y4 } \\
\text { (C2 removal) }\end{array}$} & Intercept & -207.60 & & & & & \\
\hline & A & 918.00 & 34.74 & 0.001 & 3797.9 & 32.46 & Significant \\
\hline & B & 47.85 & 33.39 & 0.001 & 3650.0 & 31.19 & Significant \\
\hline & $A^{2}$ & -954.00 & 5.79 & 0.047 & 632.9 & 5.41 & Significant \\
\hline & $\mathrm{B}^{2}$ & -2.26 & 26.29 & 0.001 & 2873.7 & 24.56 & Significant \\
\hline & $\mathrm{AB}$ & -45.50 & 6.83 & 0.035 & 746.8 & 6.38 & Significant \\
\hline
\end{tabular}



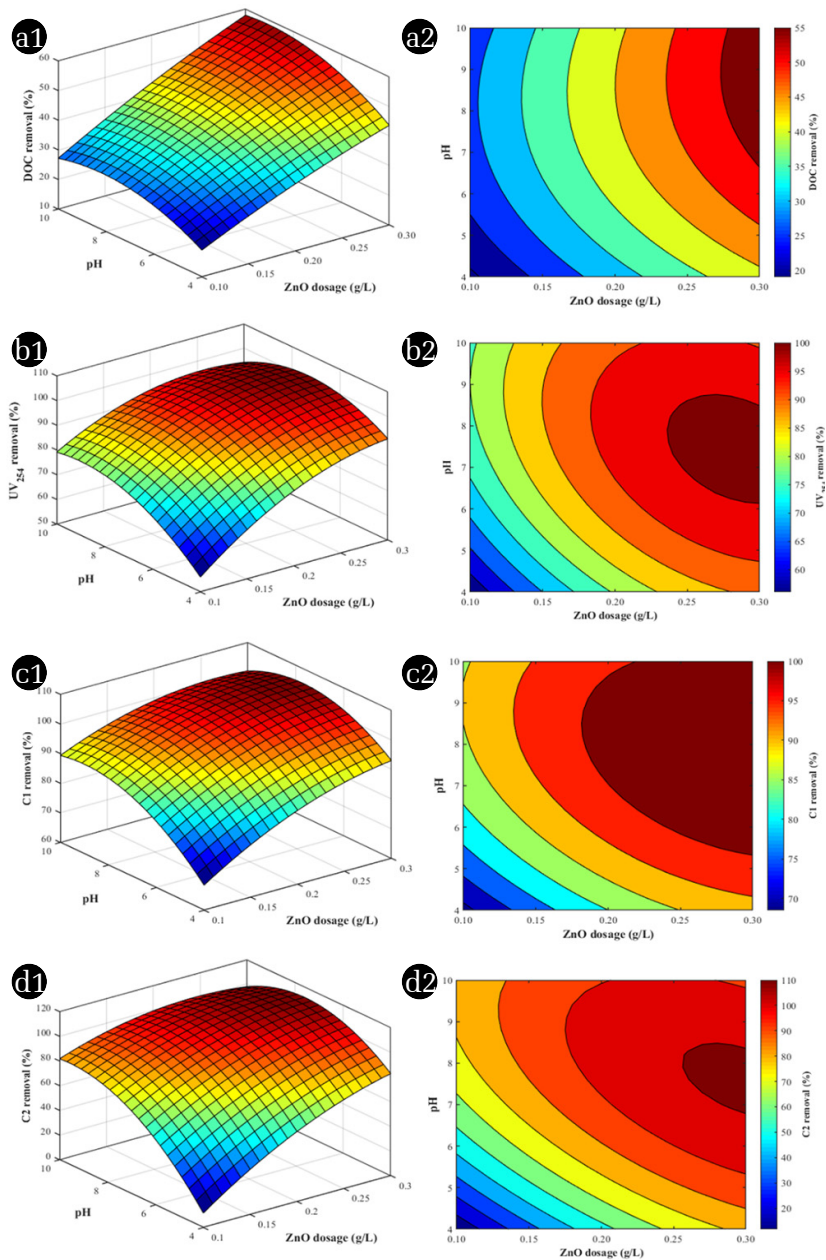

Fig. 2. $3 \mathrm{D}$ response surface graphs and $2 \mathrm{D}$ contour plots for $\mathrm{DOM}$ photocatalytic degradation: (a1) \& (a2) - DOC removal, (b1) \& (b2) - $\mathrm{UV}_{254}$ removal, (c1) \& (c2) - component 1 removal, and $(\mathrm{d} 1)$ \& (d2) - component 2 removal.

efficiency can be explained by an increased number of available active sites on the surface of photocatalyst, leading to an increase of ${ }^{\circ} \mathrm{OH}$ generation, and thus facilitating the photodegradation of DOM. Likewise, as $\mathrm{pH}$ level increased from 4 to 10, DOM removal increased by $8.07 \%$ for DOC, $23.12 \%$ for $\mathrm{UV}_{254}, 20.91 \%$ for C1, and $70.05 \%$ for $\mathrm{C} 2$ at $0.1 \mathrm{~g} / \mathrm{L}$ of $\mathrm{ZnO}$ dosage and by $14.28 \%$ for DOC, $3.54 \%$ for $\mathrm{UV}_{254}, 7.44 \%$ for $\mathrm{C} 1$, and $15.39 \%$ for $\mathrm{C} 2$ at $0.3 \mathrm{~g} / \mathrm{L}$ of $\mathrm{ZnO}$ dosage. Moreover, Figure S11 displayed the plot of $\mathrm{pH}$ effect (one of the main effects) on DOM degradation efficiency. It was observed that the DOM degradation efficiency was in the order of pH 7 (neutral) $>$ pH 10 (alkaline) $>$ pH 4 (acidic). As abovementioned in Section 3.1, this result was due to the ionization of DOM and the zeta potential of $\mathrm{ZnO}$ at different $\mathrm{pH}$ levels.

In order to optimize the operating parameters for the DOM degradation efficiency, which is expressed by the multiple responses of DOC, $\mathrm{UV}_{254}, \mathrm{C} 1$ and $\mathrm{C} 2$, a desirable function was applied in this study. The desirable function, as defined a maximum DOM degradation efficiency, was set as maximum DOC, $\mathrm{UV}_{254}, \mathrm{C} 1$ and $\mathrm{C} 2$ removals with the $\mathrm{ZnO}$ dosage in the range of $0.1 \mathrm{~g} / \mathrm{L}$ to 0.3 $\mathrm{g} / \mathrm{L}$ and within the $\mathrm{pH}$ of 4 to 10 . The optimal condition for the maximum DOM degradation was found to be at $\mathrm{ZnO}$ of $0.3 \mathrm{~g} / \mathrm{L}$ and $\mathrm{pH} 10$, in which the 180-min removals of DOC, $\mathrm{UV}_{254}, \mathrm{C} 1$ and C2 were predicted to be $57.9 \%, 94.5 \%, 100.0 \%$, and $98.0 \%$, respectively. The predicted values by the statistical model were validated by the experimental data, where the results were very close to the predicted values, showing the removals of DOC, $\mathrm{UV}_{254}$, C1 and C2 to $56.11 \%, 95.79 \%, 100.0 \%$, and 99.4\%, respectively.

\subsection{Mechanisms of Photocatalytic Degradation}

The proposed reaction mechanisms for the visible/solar photocatalytic degradation of DOM using $\mathrm{ZnO}$ are expressed in the set of equations (Eqs. (15)-(32)) (Fig. S12). Basically, when ZnO is irradiated with simulated sunlight containing photonic energy (hv), $\mathrm{h}_{\mathrm{VB}}^{+}$and conduction band (CB) electron $\left(\mathrm{e}_{\mathrm{CB}}^{-}\right)$pairs are produced, as given in Eq. (15) [21-23]. The $\mathrm{h}_{\mathrm{VB}}^{+}$reacts with $\mathrm{H}_{2} \mathrm{O}$ and hydroxide ions $\left(\mathrm{OH}^{-}\right)$to form ${ }^{\circ} \mathrm{OH}$ (Eqs. (17)-(18)) [22-24]. The reduction of dissolved or adsorbed $\mathrm{O}_{2}$ to $\mathrm{O}_{2}^{--}$by $\mathrm{CB}$ electrons is depicted in Eq. (19) [24-26]. The $\mathrm{O}_{2}^{--}$was converted to $\mathrm{H}_{2} \mathrm{O}_{2}$ via disproportionation with protons (Eq. (20)) or formed $\mathrm{HO}_{2}^{*}$ via protonation, which had a short lifetime due to the rapid reaction with $\mathrm{O}_{2}^{*-}$ or $\mathrm{HO}_{2}^{*}$ to form the more stable $\mathrm{H}_{2} \mathrm{O}_{2}$ (Eq. (21)-(22)) [23-25]. The one-electron reduction of $\mathrm{H}_{2} \mathrm{O}_{2}$ produced ${ }^{\circ} \mathrm{OH}$ (Eq. (23)), while $\mathrm{H}_{2} \mathrm{O}_{2}$ could also react with $\mathrm{O}_{2}^{--}$to form ${ }^{\circ} \mathrm{OH}$ (Eqs. (24)-(25)) [21-24]. The formation of ${ }^{\circ} \mathrm{OH}$ and $\mathrm{O}_{2}^{\cdot-}$ could attack DOM at or near the $\mathrm{ZnO}$ surface, then being able to oxidize and reduce the DOM molecules into $\mathrm{CO}_{2}, \mathrm{H}_{2} \mathrm{O}$, and degradation products (Eq. (26) [14, 26-28]. According to previous studies [5], the reaction of ${ }^{\circ} \mathrm{OH}$ with $\mathrm{HAs}$ resulted in the release of LMW acids, amino acids, and ammonia. Moreover, it has been reported that the photobleaching of DOM after irradiation of simulated sunlight generated reactive species, including singlet oxygen $\left({ }^{1} \mathrm{O}_{2}\right)$, ${ }^{\circ} \mathrm{OH}$, triplet DOM states $\left({ }^{3} \mathrm{DOM}^{*}\right)$, $\mathrm{O}_{2}^{--}$, and $\mathrm{H}_{2} \mathrm{O}_{2}$, as given in Eqs. (27)-(32) [29-31]. Although these photogenerated reactive species were produced at low concentrations and had very short-lives, they had an important role in the degradation of DOM by photocatalysis process.

$$
\begin{gathered}
\mathrm{ZnO}+\mathrm{hv} \rightarrow \mathrm{h}_{\mathrm{VB}}^{+}+\mathrm{e}_{\mathrm{CB}}^{-} \\
\mathrm{H}_{2} \mathrm{O}+\mathrm{hv} \rightarrow \mathrm{OH}^{-}+\mathrm{H}^{+} \\
\mathrm{h}_{\mathrm{VB}}^{+}+\mathrm{H}_{2} \mathrm{O} \rightarrow \mathrm{H}^{+}+\cdot \mathrm{OH} \\
\mathrm{h}_{\mathrm{VB}}^{+}+\mathrm{OH}^{-} \rightarrow \cdot \mathrm{OH} \\
\mathrm{e}_{\mathrm{CB}}^{-}+\mathrm{O}_{2} \rightarrow \mathrm{O}_{2}^{\cdot-} \\
\mathrm{O}_{2}^{--}+2 \mathrm{H}^{+}+\mathrm{e}_{\mathrm{CB}}^{-} \rightarrow \mathrm{H}_{2} \mathrm{O}_{2} \\
\mathrm{O}_{2}^{--}+2 \mathrm{H}^{+} \rightarrow \mathrm{HO}_{2}^{\cdot} \\
\mathrm{HO}_{2}^{\cdot}+\mathrm{HO}_{2}^{\cdot} \rightarrow \mathrm{H}_{2} \mathrm{O}_{2}+\mathrm{O}_{2} \\
\mathrm{H}_{2} \mathrm{O}_{2}+\mathrm{H}^{+}+\mathrm{e}_{\mathrm{CB}}^{-} \rightarrow \mathrm{H}_{2} \mathrm{O}+\cdot \mathrm{OH} \\
\mathrm{H}_{2} \mathrm{O}_{2}+\mathrm{O}_{2}^{--} \rightarrow \mathrm{OH}^{-}+\mathrm{O}_{2}+\cdot \mathrm{OH} \\
\mathrm{H}_{2} \mathrm{O}_{2}+\mathrm{hv}^{\circ} 2^{\cdot} \mathrm{OH}
\end{gathered}
$$


$\mathrm{DOM}+\cdot \mathrm{OH} / \mathrm{O}_{2}^{--} \rightarrow \mathrm{CO}_{2}+\mathrm{H}_{2} \mathrm{O}+$ Degradation products

$$
\begin{gathered}
\mathrm{DOM}+\mathrm{hv} \rightarrow{ }^{1} \mathrm{DOM}^{*} \rightarrow{ }^{3} \mathrm{DOM}^{*} \\
\mathrm{DOM}+\mathrm{hv} \rightarrow{ }^{\cdot} \mathrm{OH} \\
{ }^{3} \mathrm{DOM}^{*}+\mathrm{O}_{2} \rightarrow{ }^{1} \mathrm{DOM}+{ }^{1} \mathrm{O}_{2} \\
{ }^{3} \mathrm{DOM}^{*} \rightarrow \mathrm{DOM}^{--} \text {(electron transfer) } \\
\mathrm{DOM}^{\cdot-}+\mathrm{O}_{2} \rightarrow \mathrm{DOM}+\mathrm{O}_{2}^{\cdot-} \\
\mathrm{O}_{2}^{--}+2 \mathrm{H}^{+} \rightarrow \mathrm{H}_{2} \mathrm{O}_{2}+\mathrm{O}_{2}
\end{gathered}
$$

The photogenerated holes $\left(\mathrm{h}_{\mathrm{VB}}^{+}\right),{ }^{\circ} \mathrm{OH}$ and $\mathrm{O}_{2}^{--}$are the main ROSs involved in the photocatalytic oxidation of organic pollutants. To assess the contributions of the main ROSs to the photocatalytic reactions under simulated sunlight irradiation, we conducted the radical- and hole-trapping experiments by introducing different scavengers including 1,4-benzoquinone (BQ, 0.01M), ethylene diamine tetraacetic acid disodium salt (EDTA-2Na, 0.01M), and tert-butyl alcohol (TBA, 0.01M) as the $\mathrm{O}_{2}^{--}, \mathrm{h}_{\mathrm{VB}}^{+}$, and ${ }^{\circ} \mathrm{OH}$ scavengers, respectively. The radical- and hole-trapping experiments were carried out at an initial $\mathrm{DOM}$ concentration of $10 \mathrm{mgC} / \mathrm{L}, \mathrm{pH} 7, \mathrm{ZnO}$ concentration of $0.2 \mathrm{~g} / \mathrm{L}$, and scavenger concentration of $0.01 \mathrm{M}$. Figure S13 illustrates different photocatalytic degradations of DOM (using DOC and $\mathrm{UV}_{254}$ values) under the existence of different scavengers. Compared to the no-scavenger, the DOM removals decreased when BQ, EDTA-2Na or TBA were introduced, indicating that three ROSs contributed to the photocatalytic degradation of DOM. Specifically, the DOM removals decreased greatly when the TPA or EDTA-2Na was added, and DOC removals reduced to $7.23 \%$ and $9.82 \%$, compared to $43.14 \%$ of no-scavenger, while the $\mathrm{UV}_{254}$ removals decreased to $60.07 \%$ and $68.31 \%$ from the $95.61 \%$ of no-scavenger. Meanwhile, the presence of BQ did not significantly affect the efficiency of DOM removal, meaning that the $\mathrm{O}_{2}^{--}$could also contribute to the photocatalytic degradation of DOM, but not as much as ${ }^{\circ} \mathrm{OH}$ and the $\mathrm{h}_{\mathrm{VB}}^{+}$, and the contributing orders of active species would be ${ }^{\circ} \mathrm{OH}>\mathrm{h}_{\mathrm{VB}}^{+}>\mathrm{O}_{2}^{--}$. Based on these results, it can be concluded that the photodegradation of DOM was mainly driven by ${ }^{\circ} \mathrm{OH}$ and $\mathrm{h}_{\mathrm{VB}}^{+}$and, and the photocatalytic degradation of DOM would be promoted by synergistic actions, i.e., more generation of ${ }^{\circ} \mathrm{OH}$ and $\mathrm{h}_{\mathrm{VB}}^{+}$by visible light.

In order to assess the role of catalyst, light source, and combined catalyst and light efforts on the DOM degradation, a comparison of adsorption, photolysis, and photocatalysis of DOM was investigated under the experiment condition at $0.2 \mathrm{~g} / \mathrm{L} \mathrm{ZnO}$ and $\mathrm{pH}$ 7. The total DOM removals and degradation rates calculated using DOC and $\mathrm{UV}_{254}$ for three processes are expressed in Fig.S14. The DOC removals were $2.94 \%, 10.21 \%$, and $43.14 \%$ for photolysis, adsorption, and photocatalysis, respectively. The degradation rate for photocatalysis was higher than those for photolysis (18.56-fold) and adsorption (5.47-fold) (Fig. S14 (a)). Similarly, as shown in Fig. S14(b), $\mathrm{UV}_{254}$ removals were $4.11 \%, 19.51 \%$, and $95.61 \%$ for photolysis, adsorption, and photocatalysis, respectively. The degradation rate for photocatalysis was greater than those for photolysis (93.57-fold) and adsorption (16.96-fold). Therefore, the results demonstrated that adsorption by $\mathrm{ZnO}$ only or photolysis (sunlight only) had a minor contribution to DOM removal, whereas the photocatalysis significantly contributed to the DOM degradation.

In addition to the photocatalytic performance, the reusability of photocatalyst is also very important. To evaluate the photo-stability of the catalyst, recycled experiments for the photodegradation of DOM were performed. The experiments were implemented by recovering and reusing of $\mathrm{ZnO}$ in four serial cycles for DOM photodegradation, and the results are depicted in Fig.S15(a). After four cycles, the total removals of DOM in terms of $\mathrm{UV}_{254}$ reduced from $95.0 \%$ to $86.2 \%$. It might be due to the photocorrosion of $\mathrm{ZnO}$ under the sunlight irradiation (Eq. (33)), which is a serious drawback for ZnO-based photocatalysts [22, 44]. However, with a slight reduction in DOM degradation efficiency was observed after the four cycles, still $\mathrm{ZnO}$ could be an efficient photocatalyst for organic pollutants, and its reusability potential would be highly increased if the surface of the $\mathrm{ZnO}$ is modified. Furthermore, DOM photocatalytic efficiencies by using $\mathrm{ZnO}$ and two different $\mathrm{TiO}_{2}$ catalysts $\left(\mathrm{TiO}_{2}\right.$-AEROXIDE ${ }^{\circledR} \mathrm{P} 25$ and $\mathrm{TiO}_{2}$-Sigma Aldrich) were compared, as shown in Fig. S15 (b). The DOM removals and degradation rates based on $\mathrm{UV}_{254}$ are comparatively presented in Fig. S15 (b). As observed, the degradation of DOM by two catalysts well fitted to a pseudo-first-order model $\left(\mathrm{R}_{\mathrm{Zno}}^{2}=0.98\right.$ and $\left.\mathrm{R}_{\mathrm{TiO}_{2}}^{2}=0.95\right)$. Both the removal and degradation rate when $\mathrm{ZnO}$ was used were higher compared to the results when two types of $\mathrm{TiO}_{2}$ were used. Specifically, the DOM removal and degradation rate of $\mathrm{ZnO}$ catalyst is $\Delta=6.1 \%$ and 1.50 -fold higher than those of $\mathrm{TiO}_{2} \mathrm{P} 25$ catalyst. The DOM removal and photodegradation rate of $\mathrm{ZnO}$ catalyst is $\Delta=31.6 \%$ and 3.01-fold higher than those of $\mathrm{TiO}_{2}$ Sigma Aldrich catalyst. Therefore, we concluded that $\mathrm{ZnO}$ catalyst could be a good photocatalyst candidate for the photocatalytic degradation of DOM and other organic pollutants.

$$
2 \mathrm{ZnO}+4 \mathrm{~h}_{\mathrm{VB}}^{+} \rightarrow 2 \mathrm{Zn}^{2+}+\mathrm{O}_{2}
$$

\section{Conclusions}

This study demonstrates that $\mathrm{ZnO}$-assisted solar irradiation is one of the most promising green technologies for effective degradation of DOM in aqueous environments. DOM removal by photolysis or adsorption onto $\mathrm{ZnO}$ is negligible, and the photocatalysis plays an important role in the treatment. Tracking of DOM using EEM-PARAFAC during the photocatalytic processes shows that the degradation rates become different, depending on the characteristics of DOM. The organic matters with light-absorption and high molecular weights are degraded to low molecular weights, and non-light absorbing substances with organic carbon, resulting in lower removals of DOC than $\mathrm{UV}_{254}$ or fluorescing components. The ROS scavenging experiments providing DOM photocatalysis under sunlight irradiation, using $\mathrm{ZnO}$, are mainly driven by ${ }^{\circ} \mathrm{OH}$ and . Comparisons between $\mathrm{ZnO}$ and two types of $\mathrm{TiO}_{2}$ reveal that $\mathrm{ZnO}$-assisted photocatalysis are more efficient than those with $\mathrm{TiO}_{2}$, demonstrating it as good photoactivity under visible light, demanding low energy. The application of RSM-CCD shows an overall good fit between the model prediction and the experimental 
data, and the optimized conditions for maximum removal give insight into the practicability of the system. The sunlight-driven $\mathrm{ZnO}$ photodegradation can be further enhanced for better performance of the process by optimizing other parameters, and by modifying the photocatalytic systems.

\section{Acknowledgment}

This research was supported by research project (NRF-2015R1D1 A4A01020056) from the National Research Foundation, and the authors are grateful for the support.

\section{Author Contributions}

T.T.N. (Ph.D. student) performed the experiments as with the data preparation for PARAFAC modeling and wrote the first draft. S.-N.N. (Research Professor) conceptualized the experimental methodology, performed the data analysis on PARAFAC modeling, acquired the funding and finalized the submitted version.

\section{References}

1. Leenheer JA, Croué JP. Characterizing aquatic dissolved organic matter. Environ. Sci. Technol. 2003;37;18A-26A.

2. Sillanpää M. Natural Organic Matter in Water: Characterization and Treatment Methods. IWA Publishing; 2015.

3. Tak S, Vellanki BP. Natural organic matter as precursor to disinfection byproducts and its removal using conventional and advanced processes: State of the art review. J. Water Health 2018;16;681-703.

4. de Melo BAG, Motta FL, Santana MHA. Humic acids: Structural properties and multiple functionalities for novel technological developments. Mater. Sci. Eng. C. 2016;62;967-974.

5. Aiken GR. Humic Substances in Soil, Sediment, And Water: Geochemistry, Isolation, And Characterization. Wiley; 1985.

6. Matilainen A, Sillanpää M. Removal of natural organic matter from drinking water by advanced oxidation processes. Chemosphere 2010;80;351-365.

7. Sillanpää M, Ncibi MC, Matilainen A. Advanced oxidation processes for the removal of natural organic matter from drinking water sources: A comprehensive review. J. Environ. Manage. 2018;208;56-76.

8. Uyguner-Demirel CS, Bekbolet M. Significance of analytical parameters for the understanding of natural organic matter in relation to photocatalytic oxidation. Chemosphere 2011;84; 1009-1031.

9. Aziz KHH, Miessner H, Mueller S, et al. Degradation of pharmaceutical diclofenac and ibuprofen in aqueous solution, a direct comparison of ozonation, photocatalysis, and non-thermal plasma. Chem. Eng. J. 2017;313;1033-1041.

10. Aziz KHH, Omer KM, Mahyar A, Miessner H, Mueller S, Moeller D. Application of photocatalytic falling film reactor to elucidate the degradation pathways of pharmaceutical diclofenac and ibuprofen in aqueous solutions. Coatings 2019;9;465.
11. Hien NT, Nguyen LH, Van HT, et al. Heterogeneous catalyst ozonation of Direct Black 22 from aqueous solution in the presence of metal slags originating from industrial solid wastes. Sep. Purif. Technol. 2020;233;115961.

12. Tung TX, Xu D, Zhang Y, Zhou Q, Wu Z. Removing humic acid from aqueous solution using titanium dioxide: A review. Polish J. Environ. Stud. 2019;28;529-542.

13. Phong DD, Hur J. Insight into photocatalytic degradation of dissolved organic matter in $\mathrm{UVA} / \mathrm{TiO}_{2}$ systems revealed by fluorescence EEM-PARAFAC. Water Res. 2015;87;119-126.

14. Zhao C, Wang Z, Wang C, Li X, Wang CC. Photocatalytic degradation of DOM in urban stormwater runoff with $\mathrm{TiO}_{2}$ nanoparticles under UV light irradiation: EEM-PARAFAC analysis and influence of co-existing inorganic ions. Environ. Pollut. 2018;243; 177-188.

15. Phong DD, Hur J. Non-catalytic and catalytic degradation of effluent dissolved organic matter under UVA-and UVC-irradiation tracked by advanced spectroscopic tools. Water Res. 2016;105;199-208.

16. Valencia S, Marín JM, Restrepo G, Frimmel FH. Application of excitation-emission fluorescence matrices and UV/Vis absorption to monitoring the photocatalytic degradation of commercial humic acid. Sci. Total Environ. 2013;442;207-214.

17. Valencia S, Marín JM, Restrepo G, Frimmel FH. Evaluation of natural organic matter changes from Lake Hohloh by three-dimensional excitation-emission matrix fluorescence spectroscopy during $\mathrm{TiO}_{2} / \mathrm{UV}$ process. Water Res. 2014;51;124-133.

18. Birben NC, Uyguner-Demirel CS, Sen-Kavurmaci S, et al. Comparative evaluation of anion doped photocatalysts on the mineralization and decolorization of natural organic matter. Catal. Today 2015;240;125-131.

19. Birben NC, Uyguner-Demirel CS, Sen-Kavurmaci S, et al. Application of Fe-doped $\mathrm{TiO}_{2}$ specimens for the solar photocatalytic degradation of humic acid. Catal. Today 2017;281; 78-84.

20. Balati A, Tek S, Nash K, Shipley H. Nanoarchitecture of $\mathrm{TiO}_{2}$ microspheres with expanded lattice interlayers and its heterojunction to the laser modified black $\mathrm{TiO}_{2}$ using pulsed laser ablation in liquid with improved photocatalytic performance under visible light irradiation. J. Colloid Interface Sci. 2019;541;234-248.

21. Nguyen TT, Nam S-N, Son J, Oh J. Tungsten Trioxide $\left(\mathrm{WO}_{3}\right)$-assisted Photocatalytic Degradation of Amoxicillin by Simulated Solar Irradiation. Sci. Rep. 2019;9;1-18.

22. Kumar SG, Rao KSRK. Zinc oxide based photocatalysis: Tailoring surface-bulk structure and related interfacial charge carrier dynamics for better environmental applications. RSC $A d v$. 2015;5;3306-3351.

23. Dehghani MH, Mahdavi P. Removal of acid 4092 dye from aqueous solution by zinc oxide nanoparticles and ultraviolet irradiation. Desalin. Water Treat. 2015;54;3464-3469.

24. Balati A, Wagle D, Nash KL, Shipley HJ. Heterojunction of $\mathrm{TiO}_{2}$ nanoparticle embedded into ZSM5 to 2D and 3D layered-structures of $\mathrm{MoS}_{2}$ nanosheets fabricated by pulsed laser ablation and microwave technique in deionized water: structurally enhanced photocatalytic performance. Appl. Nanosci. 2019;9;19-32. 
25. Balati A, Matta A, Nash K, Shipley HJ. Heterojunction of vertically aligned $\mathrm{MoS}_{2}$ layers to Hydrogenated Black $\mathrm{TiO}_{2}$ and Rutile Based Inorganic Hollow Microspheres for the highly enhanced visible light arsenic photooxidation. Compos. Part B Eng. 2020;185;107785.

26. Ong CB, Ng LY, Mohammad AW. A review of $\mathrm{ZnO}$ nanoparticles as solar photocatalysts: Synthesis, mechanisms and applications. Renew. Sustain. Energy Rev. 2017;81;536-551.

27. Ahn Y, Lee D, Kwon K, Choi IH, Nam S-N, Kang JW. Characteristics and fate of natural organic matter during UV oxidation processes. Chemosphere 2017;184;960-968.

28. Oskoei V, Dehghani MH, Nazmara S, et al. Removal of humic acid from aqueous solution using $\mathrm{UV} / \mathrm{ZnO}$ nano-photocatalysis and adsorption. J. Mol. Liq. 2016;213;374-380.

29. Baycan N, Uyguner-Demirel CS, Bekbolet M. Response surface methodological approach for the assessment of the photocatalytic degradation of NOM. J. Photochem. Photobiol. A Chem. 2011;255;26-35.

30. Vione D, Minella M, Maurino V, Minero C. Indirect photochemistry in sunlit surface waters: Photoinduced production of reactive transient species. Chem. - A Eur. J. 2014;20; 10590-10606.

31. Niu X, Liu C, Gutierrez L, Crou J. Photobleaching-induced changes in photosensitizing properties of dissolved organic matter. Water Res. 2014;66;140-148.

32. Li P, Hur J. Utilization of UV-Vis spectroscopy and related data analyses for dissolved organic matter (DOM) studies: A review. Crit. Rev. Environ. Sci. Technol. 2017;47;P131-154.

33. Matilainen A, Gjessing ET, Lahtinen, Hed TL, Bhatnagar A, Sillanpää M. An overview of the methods used in the characterisation of natural organic matter (NOM) in relation to drinking water treatment. Chemosphere 2011;83;1431-1442.

34. Murphy KR, Stedmon CA, Graeber D, Bro R. Fluorescence spectroscopy and multi-way techniques. PARAFAC. Anal. Methods 2013;5;6557-6566.

35. Dehghani MH, Najafpoor AA, Azam K. Using sonochemical reactor for degradation of LAS from effluent of wastewater treatment plant. Desalination 2010;250;82-86.
36. Dehghani MH, Tajik S, Panahi A, et al. Adsorptive removal of noxious cadmium from aqueous solutions using poly urea-formaldehyde: A novel polymer adsorbent. MethodsX 2018;5;1148-1155.

37. Dehghani MH, Fadaei AM. Photocatalytic Oxidation of Organophosphorus Pesticides using Zinc Oxide. Res. J. Chem. Environ. 2012;16.

38. Dehghani MH, Kamalian S, Shayeghi M, et al. High-performance removal of diazinon pesticide from water using multi-walled carbon nanotubes. Microchem. J. 2018;145;486-491.

39. Balati A, Bazilio A, Shahriar A, Nash K, Shipley HJ. Simultaneous formation of ultra-thin $\mathrm{MoSe}_{2}$ nanosheets, Inorganic Fullerene-Like $\mathrm{MoSe}_{2}$ and $\mathrm{MoO}_{3}$ quantum dots using fast and ecofriendly Pulsed Laser Ablation in Liquid followed by microwave treatment. Mater. Sci. Semicond. Process. 2019;99;68-77.

40. Dehghani MH, Yetilmezsoy K, Salari M, Heidarinejad Z, Yousefi M, Sillanpää M. Adsorptive removal of cobalt(II) from aqueous solutions using multi-walled carbon nanotubes and $\gamma$-alumina as novel adsorbents: Modelling and optimization based on response surface methodology and artificial neural network. J. Mol. Liq. 2020;299;112154.

41. Nam S-N, Cho H, Han J, Her N, Yong J. Photocatalytic degradation of acesulfame K: Optimization using the Box - Behnken design (BBD). Process Saf. Environ. Prot. 2017;113;10-21.

42. Bindu P, Thomas S. Estimation of lattice strain in $\mathrm{ZnO}$ nanoparticles: X-ray peak profile analysis. J. Theor. Appl. Phys. 2014;8;123-134.

43. Fatehah MO, Abdul AH, Stoll S. Aggregation and disaggregation of $\mathrm{ZnO}$ nanoparticles: Influence of $\mathrm{pH}$ and adsorption of Suwannee River humic acid. Adv. Mater. Res. 2014;832;728-733.

44. Weng B, Qi MY, Han C, Tang ZR, Xu YJ. Photocorrosion Inhibition of Semiconductor-Based Photocatalysts: Basic Principle, Current Development, and Future Perspective. ACS Catal. 2019;9;4642-4687.

45. Dougherty C. Introduction to Econometrics. Oxford: Oxford University Press; 2011. 